\title{
Analytical Network Process (ANP) Based Modeling For Analysing The Risks In Traditional, Agile And Lean Supply Chain
}

\author{
Mahesh Chand and Tilak Raj \\ YMCA University of Science and Technology, Faridabad, India \\ Ravi Shankar, \\ Indian Institute of Technology Delhi, New Delhi, India
}

\begin{abstract}
Risk in the context of supply chain management plays an important role in industries. Risk can be defined as a combination of probability or frequency of occurrence of a defined hazard and magnitude of the occurrence. In this paper it is illustrate how the industries can analyse and assess the risks associated with supply chain. To fulfil customer requirements and profit maximization industries need to improve their supply chain system by eliminating risks associated to it by using appropriate tools and techniques. For the successful supply chain management, industries must have to focus on risk as a tool to achieve their goals. A comparative analysis of various risks which reduces the chance of occurrence of failures in determinants i.e. Disruption (DR), Deviation (DV) and Disasters (DS) has been analysed in this study. The purpose of this paper is to analyze the various risk factors identify through literature and case study of Indian manufacturing industries in traditional, agile and lean supply chain by the application of analytical network process (ANP). The proposed framework provides a structured approach for identifying and assessing risk and their differential impacts on different levels of supply chain networks. It provides insights into the dynamics of risk events and identifies network configurations that are vulnerable to different levels of risk.
\end{abstract}

Keywords: analytical network process, risks, supply chain

\section{Introduction}

Risk management is emerging as important contributor to the most of the fields of management and decision control. The challenge to business organizations is to mitigate that risk through creating more resilient supply chains. The motives behind the use of risk management approaches are the global competition, change in technology, and the continuous contention for competitive advantage (Brindley, 2004). Risk can be defined as a combination of probability or frequency of occurrence of a defined hazard and magnitude of the occurrence (BS 4778, 1991). Building on several authors that have defined supply

Mahesh Chand, Department of Mechanical Engineering, YMCA University of Science and Technology, Faridabad, Haryana 121006, India. Email: mchanddce@gmail.com.

Tilak Raj, Department of Mechanical Engineering, YMCA University of Science and Technology, Faridabad, Haryana 121006, India. Email: tilakraj64@gmail.com.

Ravi Shankar, Department of Management Studies, Indian Institute of Technology Delhi, New Delhi 110016, India. Email: ravi1@dms.iitd.ernet.in. 
chain risk (e.g. Choi et al., 2006; Zsidisin et al., 2000, 2004), it is an event that adversely affects supply chain operations and hence its desired performance measures, such as chain-wide service levels and responsiveness, as well as cost. Organizations generally concentrate on the type of disruption and not its source in order to know how to get it prepared against risks. The advancement of globalization in industries has been increased uncertainties and risks in both demand and supply and the likelihood of supply chain disruption, deviation and disasters.

Risk management action plans can be developed to preferably avoid the identified risks, or if not possible, at least mitigate, contain and control them. As such, this paper makes an important contribution to the area of supply chain risk management, and highlights analytical network process (ANP) approach to manage these risks in supply chain. It continues the tradition of recent academic research and industry reports, which have stressed the importance of supply chain risk management, as well as the development of approaches for its management (e.g. Blos et al., 2009; Manuj and Mentzer, 2008; Shaer and Goedhart, 2009). In this paper three types of supply chain (Traditional, agile and green) have been included to analyse the risk in supply chain.

In a traditional supply chain, the flow of materials and information is linear and from one end to the other. There is a limited collaboration and visibility. Each supply chain partner has limited information regarding. There may be some focus on end-to-end supply chain costs but due to limitations of information sharing, the costs are far from optimized in most cases.

Agility in supply chain is a business-wide capability that embraces organizational structures, information systems, logistics processes and in particular, mindsets (Power et al., 2001; Katayama and Bennett, 1999). Agility is being defined as the ability of an organization to respond rapidly to changes in demand, both in terms of volume and variety (Christopher, 2000).

Lean supply chain means developing a value stream to eliminate all waste, including time, and to ensure a level schedule. The lean and agile paradigms, though distinctly different, can be and have been combined within successfully designed and operated total supply chains (Mason-Jones and Towill, 1999).

This paper Present a framework for modelling risks in traditional, agile and lean supply chain on the basis of interdependent variables. This framework provide an add to decision makers in analyzing the various factors affecting the dimensions: plan and control risk (PCR), process risk (PR), demand risk (DR), natural and social risk (NSR) in traditional, agile \& lean supply chains for the improvement of risk in SC. In this paper analytical network process (ANP) is presented to structure the problem related to the selection of an alternatives in the form hierarchical and link the determinants, dimensions and factors of risk.

\section{Literature Review}

Definitions of risk and risk management are multifarious, and many have emerged over time of particular interest in the present study is "supply (chain) risk", which refers to risk associated with inbound supply and the subsequent impact on customers (Zsidisin, 2003). Faisal et al. (2007) gave a framework focusing on risk to small and medium-scale industries, while Williams et al. (2008) did the same work to focus on supply chain security against terrorist activity. Autry and Bobbitt (2008) analysed a structured managerial interviews concerning supply chain security, and identified factors most related to those managers' views of supply chain security. Risk events can make their preparation in dealing with risk exposure much more important, focusing 
on survival (Wu and Olson, 2009).

Risk, in the context of supply chain management, is a multi-dimensional construct (Zsidisin, 2003; Zsidisin et al., 2004). It includes both the uncertainties inherent in the operational aspects of supply chain activities, such as uncertain supply and demand, as well as disruptions to its operations resulting from natural and human-inflicted. Mitchell (1995) suggests that risk reducers include: to choose approved list of suppliers, multiple sourcing, choosing a leading organizations/companies, frequent visit to supplier operations, and to make a good communication and relation among the suppliers. It has been argued that further research into frameworks for identifying risk sources from SCM perspective might be a first step in introducing risk management into design of supply chains (Sorensen, 2005). It has been argued that in the area of SC, risk management is less understood than in other disciplines and less developed. They suggest that empirical case studies to investigate: how the organizations actually cope up with themselves to manage supply chain risk, which are the process and techniques that the firms use to identify and analyse risk in their supply chains (Khan and Burnes, 2007). Ritchie and Brindley (2007) go on to argue that in order to conduct empirical research on risk in complex supply networks, tools are required for identifying, assessing and managing risk.

Based on its nature, uncertainty in the supply chain may manifest itself in three types of determinants: disruption, Deviation and disaster (Roshan and Viswanadham, 2011).

Disruption: A disruption occurs when the structure of the supply chain system is radically transformed, through the non-availability of certain production, warehousing and distribution facilities or transportation options due to unexpected events caused by human or natural factors. Disruptions may be influenced by the distinctive supply-related characteristics of each entity, including environment, infrastructure, service delivery, inter organisational linkages (Peck, 2005), and relationships, or a combination of these factors.

Deviation: A deviation is said to have occurred when one or more parameters, such as cost, quality, delivery, lead time etc., within the supply chain system occurs from their expected or mean value, without any changes to the underlying supply chain structure. Deviation of supply network outcomes from their targets is analysed from the perspective of alternative network structures.

Disaster: A disaster is defined as a temporary irrecoverable shut-down of the supply chain network due to unforeseen catastrophic system-wide disruptions. Disasters like terrorist attacks (Tang, 2006). The conceptual framework proposed in this study is intended only for dealing with supply chain risks, which refer to variations in the distribution of outcomes from expected or agreed targets.

In the proposed ANP framework plan and control risk (PCR), process risk (PR), demand risk (DR), natural and social risk (NSR) (Chopra and Sodhi, 2004) has been considered as the risk dimensions. These dimensions are the important characteristic of traditional, agile and lean supply chain which is.

Plan and Control risks (PCR): It involves the issues related to production, material management and information technology etc. In the short term, these risks mainly concern planning of production and manufacturing operations. Plan and Control risk is characterised by the four measures: IT systems (ITS), material management (MM), production Planning (PP), sales and marketing (SM) (Moeinzadeh and Hajfathaliha, 2009).

Process risks (PR): A process means to implement a risk management plan. According to Manuj and Mentzer (2008) risk management is the making of decisions regarding risk and their subsequent 
implementation, and flows from risk estimation and risk evaluation. The risk management process is focused on understanding the risks, and minimizing their impact by addressing, e.g. probability and direct impact. Process risk is characterised by the four measures: Faulty Planning (FP), Trouble with third party logistics providers (TTPLP), human error (HE), and insufficient supply team (IST).

Demand Risks (DR): A decrease in demand by customers is considered a risk. Some companies were highly dependent on one customer, whereas others have scruple decentralized the customer structure to avoid customer risk (Manuj and Mentzer, 2008a; 2008b). Demand risk is characterised by the four measures: cancellation of orders (CO), order fulfilment errors (OFE) inaccurate forecast (IF), seasonality of product (SP) (Chopra and sodhi, 2004).

Natural and social risks (NSR): All human exertion involves uncertainty and risk. Mitroff and Alpaslan (2003) categorized emergencies and crises into three categories: natural disasters, malicious activities, and systemic failures of human systems. Nature does many things to us, disrupting our best-laid plans and undoing much of what humans have constructed. This category is probably the most common source of crises: unexpected consequences arising from overly complex systems (Perrow, 1984).

Natural and social risks (NSR) is characterised by the four measures: Crime rate (CR), machine explosion (ME), prise and currency risk (PCR), social and culture grievances (SCG)

\section{Research Methodology}

In this study a questionnaire based survey is distributed in various organizations to capture the discernment and judgement of the concerned members working in this estate. In total, questionnaires were sent to 430 Indian manufacturing industries. Out of 430 questionnaires, 87 correctly completed questionnaires were received. This is the response rate of $20.23 \%$ which is not very low for such surveys (Malhotra and Grover, 1998). Invitations to participate in the survey requested responses from those experts who have experienced in this field of managing supply chain and logistics. The researchers framed the questionnaire based on 5 point likert scale, where 1 meant "Not at all" and 5 meant "very important". A postal survey questionnaire was used as the research instrument. The questionnaire is focused on the importance of select risk issues that clarified from literature review and from the survey.

\section{Development of ANP Model for Analysing the risk in Supply chain: The decision Environment}

The Network representation of the ANP model and its decision environment is shown in Fig. 1. It can be seen that the overall objective is to analyse the risk in supply chain. The determinants of risk are (Disruption (DR), Deviation (DV) and Disasters (DS)) are modeled to have dominance over the dimensions of the risk in supply chain. The risk factors are those that assist in achieving the dimension of risk in supply chain. Thus, these are dependent on the dimension. Also, there are some interdependencies among the factors, hence the arrow showing the relationship among the factor's in the network (Fig. 1). For example, PP (Production Planning.) and SM (Sales marketing) are interdependent to one another at instant. In order to achieve Production Company should focus on sales and planning also.

The alternatives consider in this case are traditional supply chain (TSC), agile supply chain (ASC), lean supply chain (LSC) for the risk in supply chain. The overall objective of this this model is to select the best framework for analyse the select risk in supply chain. 


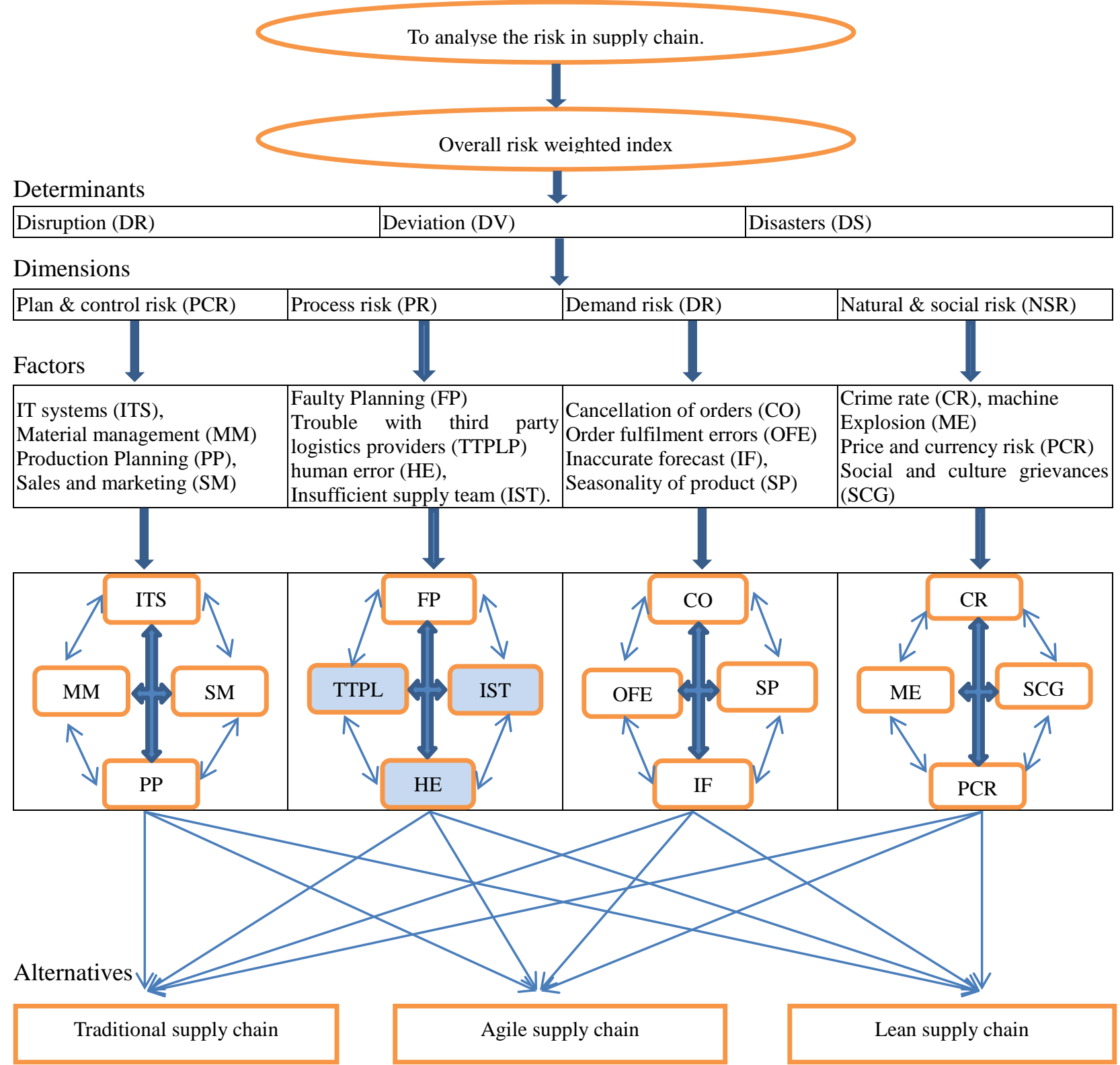

Figure 1. The Network representation of the ANP model and its decision environment.

\section{Justification for using analytical network process (ANP)}

There are numerous MADM approaches available in the literature such as AHP, ELECTRE, TOPSIS, ECA etc. Among these models the most widely used method is AHP (Saaty, 1980). AHP can be applied to this problem also but it is not utilized over because of its limitations. Sarkis and Tulluri (2002) have listed out the various limitations of AHP over ANP. Among all of these models ANP has the capability to incorporate such relationships which involve multiple factors and relationship may exist between these factors, one factor may affect the other factors and the degree of such relationship may vary between factors. Interdependencies among the factors may be represented by two-way arrows and four-ways arrows between levels, or if within the same level of analysis (Meade and Sarkis, 1998). The ANP approach is capable of handling interdependence among elements by obtaining weights through the development of a „supermatrix (Hamalainen and Seppalainen 

THE RISKS IN TRADITIONAL, AGILE AND LEAN SUPPLY CHAIN

1986).

ANP (Saaty, 1996) is a extensive decision-making technique that captures the outcome of the dependence and feedback within and between the clusters of elements. Analytical Hierarchy Process (AHP) serves as the initial stage of ANP. The ANP is a combination of two parts, where the first consists of a control hierarchy or network of criteria and sub-criteria that controls the interactions, while the second part is a network of influences among the elements and clusters. The main reason behind choosing the ANP in our case is for selecting the best alternatives.

\section{Application of ANP for risk Analysis}

The ANP model that is presented in this research has been evaluated in Indian manufacturing industries, who were interested in reducing the risk in supply chain. Industries are interested to adopt a systematic way to determine the best possible option for analysing the risk. This case experience helps us to understand in a better way of ANP methodology how to deal with risk in supply chain. The analysis and the implementation of the ANP methodology are presented in the paper illustrated below.

\section{Step 1. Model development and formulation}

In this step, the decision problem is structured into its important factors. The relevant criteria and alternatives are chosen on the basis of the review of literature and discussion with few both from industry and academia expert. The relevant criteria and alternatives are structured in the form of a control hierarchy where the criteria at the top level in the model have the highest strategic value. The top-level criteria in this model are Disruption (DR), Deviation (DV) and Disasters (DS). These three criteria are termed as the determinants. In the second level of hierarchy, four sub-criteria termed as dimensions of the model is placed which supports all the four determinants at the top level of hierarchy. These are plan and control risk (PCR), process risk (PR), demand risk (DR), natural and social risk (NSR). For example, plan and control risk helps in reducing the three determinants of DR, DV, and DS. Similar relationships are applicable for PR, DR and NSR. In this ANP model, each of the four dimensions has some factor, which helps to achieve that particular dimension. For example, the dimension DR is supported by the factors CO, OFE, IF and SP.

\section{Step 2. Pair-wise comparison of three determinants}

In this step, the decision maker is asked to respond to a series of pair-wise comparisons where two components at a time are compared with respect to an upper level 'control' criterion. These comparisons are made so as to establish the relative importance of determinants in achieving the case company's objectives. In such comparisons, a scale of $1-5$ is used to compare two options (Saaty, 1980). In this score of 1 indicates that the two options under comparison have equal importance, while a score of 5 indicates the overwhelming dominance of the component under consideration (row component) over the comparison component (column component) in a pair-wise comparison matrix. In case, a component has weaker impact than its comparison component, the range of the scores will be from 1 to $1 / 5$, where 1 indicates indifference and 1/5 represents an overwhelming dominance by a column element over the row element. For the reverse comparison between the components already compared, a reciprocal value is automatically assigned within the matrix, so that in a matrix aijaji=1. The matrix showing pair-wise comparison of determinants along with the e-vectors of these determinants is shown in Table 1.

In this paper, a two-stage algorithm (Saaty, 1980) is used for computing e-vector. These e-vectors would be used in Table 9 for the calculation of supply chain overall risk weighted index (SCORWI) for alternatives. 
Table 1

Pair-wise comparison of determinants

\begin{tabular}{llll}
\hline Determinants & DV & DR & DS \\
\hline e-vectors & .2974 & .5503 & .1523 \\
\hline
\end{tabular}

\section{Step 3. Pair-wise comparison of dimensions}

In this step, a pair-wise comparison matrix is prepared for determining the relative importance of each of the dimensions of risk (PCR, PR, DR and NSR) on the determinant. In the model, four such matrices would be formed one for each of the determinant. One such matrix for the disruption determinant is shown in Table 2. From this table, the results of the comparison (e-vectors) of the dimensions for the determinant are carried as Pja in Table 8.

\section{Step 4. Pair-wise comparison matrices between component/factor levels}

In this step, the decision maker is asked to respond to a series of pair-wise comparisons where two components would be compared at a time with respect to an upper level control criterion. The pair-wise comparison matrix for the dimension PR under the DR determinant is shown in Table 3. For the pair-wise comparison, the question asked to the decision maker is, 'what is the relative impact on process risk by Factor $\mathrm{X}$ when compared to Factor $\mathrm{Y}$, in improving the deviation? In Table 3, the relative importance of HE when compared to FT with respect to PR, in achieving the disruption is five. From Table 3 it is also observed that for the case study, the Factor HE has the maximum influence (0.5079) on PR in improving the deviation. Similarly, FP has the minimum influence (0.0533) on PR in improving the disruption. The e-vectors obtained from these matrices are imported as AD kja in Table 8.

Table 2

Pair-wise comparison of disruption determinant

\begin{tabular}{lcccc}
\hline Disruption & PCR & PR & DR & NSR \\
\hline e-vectors & .2000 & .3836 & .1638 & .2526 \\
\hline
\end{tabular}

Table 3

Pair-wise comparison matrix for the dimension PR under the DR determinant

\begin{tabular}{lllll}
\hline Process risk (PR) & FT & TTPLP & HE & IST \\
\hline e- vectors & .0533 & .2356 & .5079 & .2032 \\
\hline
\end{tabular}

\section{Step 5. Pair-wise comparison matrices of interdependencies}

Pair-wise comparisons are done to consider the interdependencies among the factors. One such comparison is presented in Table 4, which shows the result of DR-PR cluster with FP as the control attribute over other factors. For example, 'when considering FP, with regards to improve the disruption, what is the relative impact of TTPLP when compared to HE?' From Table 4, it is observed that TTPLP (0.5304) has the maximum impact on DR-PR cluster with FP as the control Factor over others. The e-vectors from matrix in Table 4 have been used in fifth column of the super matrix in Table 6.

\section{Step 6. Evaluation of alternatives (Traditional, agile and lean supply chain)}

The final set of pair-wise comparisons is made for the relative impact of each of the alternatives (TSC, ASC and LSC) on the factors in influencing the determinants. The number of such pair-wise comparison matrices is dependent on the number of factors that are included in each of the determinants. In our present case, 
there are 16 factors for each of the determinants, which lead to 48 such pair-wise matrices. One such pair-wise comparison matrix is shown in Table 6. These e-vectors from this matrix are used in columns 6, 7\& 8 of compatibility desirability indices matrix in Table 8 . The columns $6,7 \& 8$ in Table 8 correspond to TSC, ASC and LSC, respectively.

Table 4

Result of DR-PR cluster with FP as the control attribute over other factors

\begin{tabular}{llll}
\hline Faulty Planning (FP & TTPLP & HE & IST \\
\hline e-vectors & .5304 & .3596 & .1100 \\
\hline
\end{tabular}

Table 5

E- vectors of alternatives

\begin{tabular}{llll}
\hline Faulty Planning (FP) & TSC & ASC & LSC \\
\hline e-vectors & .1095 & .5812 & .3093 \\
\hline
\end{tabular}

\section{Step 7. Super matrix formation and illustration}

The super matrix allows for a resolution of the interdependencies that exist among the elements of a system. One such super matrix M, shown in Table 6, presents the results of the relative importance measures for each of the factors for the disruption determinant.

The values of the elements of the super matrix $M$ have been imported from the pair-wise comparison matrices of interdependencies (Table 4). As there are 16 such pair-wise comparison matrices, one for each of the interdependent factors in the disruption, there will be 16 non-zero columns in this super matrix. Raising the super matrix $\mathrm{M}$ to the power $2^{\mathrm{K}+1}$, where $\mathrm{k}$ is an arbitrarily large number, allows for the convergence of the interdependent relationships (Meade \& Sarkis, 1999). In this case, convergence is reached at $\mathrm{M}^{16 .}$ The converged super matrix is shown in Table 7.

Table 6

Super matrix $M$ for disruption before convergence

\begin{tabular}{|c|c|c|c|c|c|c|c|c|c|c|c|c|c|c|c|c|}
\hline & ITS & MM & $\mathrm{PP}$ & $\mathrm{SM}$ & FP & TTPLP & $\mathrm{HE}$ & IST & $\mathrm{CO}$ & OFE & IF & SP & CR & $\mathrm{ME}$ & PCR & SCG \\
\hline ITS & 0 & .2744 & .1933 & .3179 & & & & & & & & & & & & \\
\hline MM & .2883 & & .2896 & .0898 & & & & & & & & & & & & \\
\hline $\mathrm{PP}$ & .5153 & .5473 & & .5923 & & & & & & & & & & & & \\
\hline SM & .1964 & .1783 & .5171 & & & & & & & & & & & & & \\
\hline $\mathrm{FP}$ & & & & & 0 & .2383 & .2835 & .2846 & & & & & & & & \\
\hline TTPLP & & & & & .5304 & & .4488 & .5145 & & & & & & & & \\
\hline $\mathrm{HE}$ & & & & & .3596 & .4954 & 0 & .2009 & & & & & & & & \\
\hline IST & & & & & .1100 & .2663 & .2677 & 0 & & & & & & & & \\
\hline $\mathrm{CO}$ & & & & & & & & & 0 & .2351 & .2051 & .2601 & & & & \\
\hline OFE & & & & & & & & & .5157 & 0 & .7163 & .4438 & & & & \\
\hline IF & & & & & & & & & .4258 & .4778 & & .2961 & & & & \\
\hline SP & & & & & & & & & .0585 & .2871 & .07860 & & & & & \\
\hline CR & & & & & & & & & & & & & 0 & .6510 & .2115 & .6241 \\
\hline $\mathrm{ME}$ & & & & & & & & & & & & & .4216 & 0 & .1423 & .3334 \\
\hline PCR & & & & & & & & & & & & & .3212 & .1237 & 0 & .0425 \\
\hline SCG & & & & & & & & & & & & & .2572 & .2253 & .6462 & 0 \\
\hline
\end{tabular}


Table 7

Super matrix $M^{16}$ for disruption after convergence

\begin{tabular}{|c|c|c|c|c|c|c|c|c|c|c|c|c|c|c|c|c|}
\hline & ITS & $\mathrm{MM}$ & $\mathrm{PP}$ & $\mathrm{SM}$ & FP & TTPLP & $\mathrm{HE}$ & IST & $\mathrm{CO}$ & OFE & IF & SP & CR & $\mathrm{ME}$ & PCR & SCG \\
\hline ITS & .2014 & .2014 & .2014 & .2014 & & & & & & & & & & & & \\
\hline MM & .1845 & .1845 & .1845 & .1845 & & & & & & & & & & & & \\
\hline PP & .3570 & .3570 & .3570 & .3570 & & & & & & & & & & & & \\
\hline SM & .2571 & .2571 & .2571 & .2571 & & & & & & & & & & & & \\
\hline FP & & & & & .2094 & .2094 & .2094 & .2094 & & & & & & & & \\
\hline TTPLP & & & & & .3299 & .3299 & .3299 & .3299 & & & & & & & & \\
\hline $\mathrm{HE}$ & & & & & .2759 & .2759 & .2759 & .2759 & & & & & & & & \\
\hline IST & & & & & .1848 & .1848 & .1848 & .1848 & & & & & & & & \\
\hline $\mathrm{CO}$ & & & & & & & & & .1859 & .1859 & .1859 & .1859 & & & & \\
\hline OFE & & & & & & & & & .3731 & .3731 & .3731 & .3731 & & & & \\
\hline IF & & & & & & & & & .2994 & .2994 & .2994 & .2994 & & & & \\
\hline SP & & & & & & & & & .1415 & .1415 & .1415 & .1415 & & & & \\
\hline CR & & & & & & & & & & & & & .3494 & .3494 & .3494 & .3494 \\
\hline $\mathrm{ME}$ & & & & & & & & & & & & & .2511 & .2511 & .2511 & .2511 \\
\hline PCR & & & & & & & & & & & & & .1537 & .1537 & .1537 & .1537 \\
\hline SCG & & & & & & & & & & & & & .2458 & .2458 & .2458 & .2458 \\
\hline
\end{tabular}

\section{Step 8. Selection of the best alternative for a determinant}

The selection of the best alternative depends on the outcome of the 'desirability index'. The desirability index, Dia, for the alternative i and the determinant $X$ is defined as (Meade \& Sarkis, 1999)

$\mathrm{Dia}=\sum_{j=1}^{j} \sum_{k=1}^{k j a} \quad \operatorname{Pja~A}^{\mathrm{D}}$ kja A $\mathrm{A}^{\mathrm{I}}$ kja Sikja;

Table 8 shows the desirability indices for the compatibility determinant (DR Disruption).

These weights are used to calculate a score for the determinants of supply chain overall risk weighted index (SCORWI) for each of the alternative being considered. In Table 8, the values of second column are imported from Table 2, which are obtained by comparing the relative impact of the dimensions on the deviation determinant.

Table 8

\begin{tabular}{lllllllllll}
\hline Dimensions & $\mathrm{P}_{\mathrm{ja}}$ & Factors & $\mathrm{A}^{\mathrm{D}_{\mathrm{kja}}}$ & $\mathrm{A}^{1}{ }_{\mathrm{kja}}$ & $\mathrm{S}_{1 \mathrm{kja}}$ & $\mathrm{S}_{2 \mathrm{kja}}$ & $\mathrm{S}_{3 \mathrm{kja}}$ & $\mathrm{TSC}$ & ASC & LSC \\
\hline PCR & .2000 & ITS & .4514 & .2014 & .1649 & .1377 & .6982 & .0029 & .0025 & .0126 \\
PCR & .2000 & MM & .2110 & .1845 & .1112 & .3268 & .4520 & .0008 & .0025 & .0035 \\
PCR & .2000 & PP & .2040 & .3570 & .1792 & .3557 & .4651 & .0026 & .0051 & .0067 \\
PCR & .2000 & SM & .1336 & .2571 & .3680 & .3053 & .3267 & .0025 & .0020 & .0022 \\
& & & & & & & & & \\
PR & .3836 & FP & .0533 & .2094 & .0672 & .3568 & .5760 & .0002 & .0015 & .0024 \\
PR & .3836 & TTPLP & .2356 & .3299 & .1095 & .5812 & .3093 & .0032 & .0173 & .0092 \\
PR & .3836 & HE & .5079 & .2759 & .3251 & .2414 & .4334 & .0174 & .0129 & .0232 \\
PR & .3836 & IST & .2032 & .1848 & .2565 & .5686 & .1749 & .0036 & .0081 & .0025 \\
& & & & & & & & & & \\
DR & .1638 & CO & .3124 & .1859 & .4703 & .3222 & .2075 & .0044 & .0030 & .0019 \\
DR & .1638 & OFE & .8232 & .3731 & .0630 & .8995 & .0375 & .0031 & .0300 & .0170 \\
DR & .1638 & IF & .2031 & .2994 & .1861 & .3433 & .4705 & .0018 & .0034 & .0046 \\
DR & .1638 & SP & .4013 & .1415 & .3337 & .3663 & .3000 & .0031 & .0034 & .0027 \\
& & & & & & & & & \\
NSR & .2526 & CR & .4214 & .3494 & .5471 & .2413 & .2111 & .0203 & .0089 & .0078 \\
NSR & .2526 & ME & .3021 & .2515 & .1551 & .2376 & .6073 & .0029 & .0045 & .0116 \\
NSR & .2526 & PCR & .2562 & .1537 & .1261 & .5665 & .3074 & .0012 & .0056 & .0030 \\
NSR & .2526 & SCG & .0203 & .2458 & .3432 & .2213 & .4355 & .0004 & .0002 & .0005 \\
& & & & & & & & .0704 & .1261 & .0962 \\
\hline
\end{tabular}



THE RISKS IN TRADITIONAL, AGILE AND LEAN SUPPLY CHAIN

The values in the fifth column of Table 8 are the stable independent weights of factors obtained through converged super matrix (Table 7). The next three columns are from the pair-wise comparison matrices giving the relative impact of each of the alternatives on the factors. The final three columns represent the weighted values of the alternatives (Pja X $\mathrm{A}^{\mathrm{D}} \mathrm{kja} X \mathrm{~A}^{\mathrm{I}}$ kja X Sikja) for each of the factors. For the purpose of illustration, the value corresponding to TSC for PP is $0.0026=(0.2000 \times 0.2040 \times 0.3570 \times 0.1792=0.0026)$. The summations of these results, for the disruption of each of these alternatives, are presented in the final row of Table 8. These results indicate that the ASC with a value of 0.1261 has maximum influence on the disruption. It is followed by LSC (0.0962) and TSC (0.0704). Till this step, the analysis has been conducted only for the disruption determinant. Similar analysis is carried out for other determinants.

\section{Step 9. Output analysis of supply chain overall risk weighted index (SCORWI)}

The SCORWI for an alternative i (SCORWIi) is the summation of the products of the desirability indices (Dia) and the relative importance weights of the determinants (Ca) of the Supply chain overall risk weighted index. It is represented as:

$$
\text { SCORWIi }=\sum \text { DiaCa }
$$

For example, the SCORWI for LSC is calculated as:

$$
\text { SCORWI LSC }=[(.2974 \times \text {.1425 })+(.5503 \times \text {.0962 })+(.1523 \times .0972)]=.1100
$$

The final results are shown in Table 9.

It is observed from Table 9 that ASC is the most-suited alternative among the consider alternatives of risk in SC for this study. LSC and TSC follow this alternative. It is observed from Table 9 that disruption plays a major role in the conduct of risk in SC. It is also observed from the second column of this table that ASC (0.1672) is found to be more economic as compared to LSC (0.1425) and TSC (0.0253).

Table 9

\begin{tabular}{lllll}
\hline Alternative & .2974 & .5503 & .1523 & SC overall risk weighted index \\
Weights & (DV) & (DR) & (DS) & .0482 \\
\hline TSC & .0253 & .0704 & .0132 & .1499 \\
ASC & .1672 & .1261 & .1707 & .1110 \\
LSC & .1425 & .0962 & .0972 & \\
\hline
\end{tabular}

\section{Conclusions}

The ANP model presented in this paper structured the problem of conduct the risk in supply chain in a hierarchical form and linked the determinants, dimensions, and factors of the risk in supply chain and the alternatives available to the decision maker for various types of supply chain. Even after making contriver strategies and prioritizing the risk factors in supply chain in context to Indian manufacturing organizations, all risks cannot be invalidated. Risk planning provides an organization with a more mature decision making process in facing unexpected losses being caused by unexpected events. Existence of supply chain can be seen in both service industries as well as in manufacturing industries and the complexity variation occurs from industries to industries and from firm to firm. With this the plan and control risk, process risks, demand risks, natural and social risk dimensions can be considered as important issues in order to manage the supply chain risks. This study provides a partial support for managing the risk issues in context to supply chain. This supply chain overall risk weighted index (SCORWI) would help industries to identify, assess, plan and manage for risk. It is expected that the outcome of the results from this research study will be beneficial to the industries, which 
wishes to leverage the benefits of risk in supply chain. If the risks are being controlled effectively the efficiencies of supply chain would maintain a balance between financial management and the customer requirements. Sensitivity analyses could be done for conducted a range of feasible values and investigating their impact on risks.

\section{Limitations and Implication for Industries}

The model developed in this paper has a few limitations too. The analysis using ANP is relatively hinder as in the present work a large numbers of pair-wise comparison matrices are required. To come to a conclusion at the relationship among factors, it requires long and tending to exhaust discussion with experts from the case of risks in supply chain. Therefore, the advantages of ANP technique could be derived for making strategic decisions that are vital for the growth and survival of supply chains. The values for pair-wise comparisons depend on the knowledge of the decision-makers. Therefore group of decision-makers should include those experts who understand the implications of factors on the risk in supply chain in traditional, agile and lean supply chain. The proposed framework has been developed for risk in supply chain in Indian manufacturing industries; this framework will help the industries for analysing and managing the risks in supply chain. This research study aimed specifically to manufacturing organizations. Apart from manufacturing in particular the researchers also can consider other variety of industries like pharma, Retail, aviation, construction, etc.

\section{References}

Autry \& Bobbitt. (2008). Supply chain security orientation: conceptual development and a proposed framework. International Journal of Logistics Management, 19(1), 42-64.

Blos, M.F., Quaddus, M., Wee, H.M. \& Watanabe, K. (2009). Supply chain risk Management (SCRM): a case study on the automotive and electronic industries in Brazil. Supply Chain Management: An International Journal, 14 (4), $247-252$.

Brindley, C. (Ed.) (2004). Supply Chain Risk. Aldershot: Ashgate, 28-42.

BS 4778, (1991). Quality Vocabulary, British Standards Institute.

Chopra, S. \& Sodhi, M.S. (2004). Managing risk to avoid supply-chain breakdown, in: MIT Sloan Management Review, 46(1), 53-61.

Choi, T.Y. \& Krause, D.R. (2006). The supply base and its complexity: implications for transaction costs, risks, responsiveness, and innovation. Journal of Operations Management, 24, ( 5), 637-652.

Christopher, M., (2000). The agile supply chain, competing in volatile markets. Industrial Marketing Management 29, 37-44.

Faisal M.N., D.K. Banwet D. K. \& Shankar R. (2007). Information risks management in supply chains: an assessment and factor framework. Journal of Enterprise Information Management 20 (6), 677-699.

Hämäläinen, R.P. \& Seppäläinen, T.O. (1986). The analytic network process in energy policy making. Socio-Economic Planning Sciences, 20, 399-405.

Katayama, H. \& Bennett, D., (1999). Agility, adaptability and leanness: A comparison of concepts and a study of practice. International Journal of Production Economics 62 (1/2), 43-51.

Khan, O. \& Burnes, B. (2007). Risk and supply chain management: creating a research agenda. International Journal of Logistics Management, 18 (2), 197-216.

Malhotra, M.K. and Grover, V. (1998), “An assessment of survey research in POM: from constructs to theory”, Journal of OperationsManagement, 16 (17), 407-25.

Manuj, I. \& Mentzer, J. (2008a). Global supply chain risk management strategies. International Journal of Physical Distribution \& Logistics Management, 38 (3), 192-223.

Manuj, I. \& Mentzer, J.T. (2008b). Global supply chain risk management. Journal of Business Logistics, 29 (1), $133-56$.

Mason-Jones, R. \& Towill, D.R., (1999). Total cycle time compression and the agile supply chain. International Journal of Production Economics 62, 61-73.

Meade, L. \& Sarkis, J. (1998). Strategic Analysis of Logistics and Supply Chain Management Systems Using the Analytical 

THE RISKS IN TRADITIONAL, AGILE AND LEAN SUPPLY CHAIN

Network Process, in: Transportation Research Part E:Logistics and Transportation Review, 34,(3), 201-215.

Meade, L. \& Sarkis, J. (1999). A methodology for analyzing alternatives for agile manufacturing business processes. International Journal of Production Research, 37(2), 241-261.

Mitroff, I. \& Alpasan, M. (2003). Preparing for evil. Harvard Business Review, 81 (4), 109-15.

Mitchell, V.W. (1995). Organizational risk perception and reduction: a literature review”, British Journal of Management, 6 (2), 115-33.

Moeinzadeh, P.A. \& Hajfathaliha (2009). A Combined Fuzzy Decision Making Approach to Supply Chain Risk Assessment. World Academy of Science Engineering and Technology, 60 ,510-535.

Peck, H. (2005). Drivers of supply chain vulnerability: an integrated framework. International Journal of Physical Distribution \& Logistics Management, 35(4),. 210-232.

Perrow, C. (1984). Normal Accidents: Living with High-risk Technologies, Princeton University Press, Princeton, NJ (1999 reprint).

Power, D.J., Sohal, A.S. \& Rahman, S. (2001). Critical success factors in agile supply chain management: An empirical study. International Journal of Physical Distribution and Logistics, 31 (4), 247-265.

Ritchie, B. \& Brindley, C. (2007). An emergent framework for supply chain risk management and performance measurement. Journal of the Operational Research Society, 58, 1398-1411.

Saaty, T. L. (1980). The Analytic Hierarchy Process - Planning, Priority Setting, Resource Allocation. New York - Saint Louis San Francisco.

Saaty, T.L. (1996). Decision making with dependence and feedback: the analytic network process. Pittsburgh: RWS Publication.

Sarkis, J., \& Tulluri, S. (2002). A Model for Strategic Supplier Selection. Journal of Supply Chain Management, 38, 18-28.

Shaer, S., Goedhart, J. (2009). Risk and the consolidated supply chain: rethinking established best practices", APICS Magazine, July/August, 41-3.

Sorensen, L. (2005). How risk and uncertainty is used in supply chain management: a literature study. International Journal of Integrated Supply Management, 1(4), 387-409.

Tang, C.S. (2006). Perspectives in supply chain risk management. International Journal of Production Economics, 103 (2), 451-88.

Williams, Z. Lueg JE., Le May, SA. (2008). Supply chain security: an overview and research agenda. International Journal of Logistics Management The, 19 (2), 254-281.

Wu, D. \& Olson, D.L. (2009a). Enterprise risk management: small business scorecard analysis. Production Planning \& Control, 20 (4), 362-369.

Zsidisin G. A., Anelli A, Upton, R. (2000). Purchasing organization involvement in risk assessments, contingency plans, and risk management: an exploratory study. Supply Chain Managment, 5(4), 187-198.

Zsidisin, G.A. (2003). Managerial perceptions of supply risk, in: Journal of Supply chain management. A Global Review of Purchasing and Supply, 39 (1), 14-25.

Zsidisin, G.A., Ellram, L.M., Carter, J.R. \& Cavinato, J.L. (2004). An analysis of supply risk assessment techniques. International Journal of Physical Distribution \& Logistics Management, 34 (5), 397-413. 